\title{
Multimodal Monitoring With Haemodynamic Optimisations May Offer Some Benefit for Patients Undergoing Major Abdominal Surgery. A Randomised, Controlled Trial.
}

\section{Matej Jenko}

Ljubljana University Medical Centre https://orcid.org/0000-0002-1134-8075

Katarina Mencin

UMC Ljubljana

Vesna Novak-Jankovic

UMCN: Radboudumc

Alenka Spindler-Vesel ( $\square$ alenka.spindler@guest.arnes.si )

UMCN: Radboudumc

\section{Research}

Keywords: postoperative complications, intraoperative monitoring, multimodal monitoring, haemodynamic monitoring, cerebral tissue oxygenation, abdominal surgery

Posted Date: September 16th, 2020

DOI: https://doi.org/10.21203/rs.3.rs-73490/v1

License: (9) This work is licensed under a Creative Commons Attribution 4.0 International License.

Read Full License 
Title:

Multimodal monitoring with haemodynamic optimisations may offer some benefit for patients undergoing major abdominal surgery. A randomised, controlled trial.

Short title: Surgical outcome and multimodal monitoring (SOMM)

Matej Jenko https://orcid.org/0000-0002-1134-8075

Katarina Mencin

Vesna Novak-Jankovic

Alenka Spindler-Vesel

University Medical Centre Ljubljana

Zaloska cesta 2

SI 1000 Slovenia

Corresponding author:

Alenka Spindler - Vesel

Alenka.spindler@guest.arnes.si

Conflict of interests: None to declare.

ClinicalTrials.gov Identifier: NCT02293473 
Background: Combined monitoring of blood flow with assessment of fluid status and cerebral tissue oxygenation improve perioperative management and outcome of high-risk surgical patients. The study tests if intraoperative multimodal monitoring reduces postoperative morbidity and duration of hospitalisation in patients undergoing major abdominal surgery managed by same anaesthetic protocols with epidural analgesia.

Methods: Prospective study was conducted in 2 parallel groups. High risk surgical patients undergoing major abdominal surgery were randomised in control group (CG), where standard monitoring was applied and protocol group (PG), where cerebral oxygenation and haemodynamic monitoring were used with protocol for intraoperative interventions.

Results: There was no difference in median length of hospital stay, CG 9 days (IQR 8 days), PG 9 (5.5), $p=0.851$. There was no difference in postoperative renal of cardiac impairment. Procalcitonin was significantly higher (highest postoperative value in first 3 days) in CG, $0.75 \mathrm{mcg} / \mathrm{L}$ (IQR $3.19 \mathrm{mcg} / \mathrm{L}$ ), than in $P G 0.3 \mathrm{mcg} / \mathrm{L}(0.88 \mathrm{mcg} / \mathrm{L}), \mathrm{p}=0.001$. Patents in $\mathrm{PG}$ received larger intraoperative amount of fluids; median intraoperative fluid balance $+1300 \mathrm{ml}$ (IQR 1063ml) than CG; $+375 \mathrm{ml}$ (IQR 438ml), $\mathrm{p}<0.00$.

Conclusions: There was no difference in postoperative morbidity or hospital stay. Median postoperative value of procalcitonin was significantly higher in CG and was above laboratory reference range. There were significant differences in intraoperative fluid management.

Keywords: postoperative complications, intraoperative monitoring, multimodal monitoring, haemodynamic monitoring, cerebral tissue oxygenation, abdominal surgery

Trial registration: ClinicalTrials.gov, NCT02293473, Registered June 10, 2014, https://clinicaltrials.gov/ 


\section{Declarations}

All patients provided written letter of consent. Study was approved by National medical ethics commission.

All data are available in anonymised electronic spreadsheet form.

All the stated authors were actively involved in data collection and writing of the article. Funding was provided by University research founds.

We have no conflicts of interest to declare. 


\section{Introduction}

Continuous intraoperative measurement of blood flow and related variables was studied several times to show the benefit for the patients. New monitors and treatment protocols with predefined treatment limits (goal-directed optimization of hemodynamic parameters) suggested improvement in long-term patient outcome and reduction in morbidity and mortality by over $50 \%$ in some studies (1-4). They aim towards optimisation of microcirculation and improvement of oxygen delivery with correcting specific haemodynamic parameters(5). Benefit of individualised, targeted oxygen delivery algorithms incorporating both fluid resuscitation and vasoactive drugs applied to high-risk surgical patients was shown (6). However, flow monitoring on its own when added to conventional monitoring has much lesser effect on improving outcome and reducing mortality than anticipated $(7,8)$. In a Cochrane collaboration review, the investigators noted when using this strategy there was no decrease in mortality and length of stay was decreased on average by only one day (7). The Optimise trial did not reduce a composite outcome of complications or 30 day mortality (8). In addition to hemodynamic variables, other important parameters such as regional cerebral oxygenation (rSO2), measured by near infrared spectroscopy (NIRS) should be continuously monitored to improve outcome. Especially in the elderly, reduction in regional cerebral oxygenation may lead to poor outcome (9-11). Monitors which assess the degree of cortical suppression (e.g. BIS, Aspect Medical Systems, Cambridge, USA) facilitates anaesthetic titration and has been shown to reduce anaesthetic exposure $(12,13)$.

In most studies, all new methods have been studied separately and there is a lack of studies to show the effect of combined (multimodal) monitoring on mortality and occurrence of complications. All gathered data indicate that the combined use of new methods (monitoring blood flow with assessment of fluid status, depth of anaesthesia and tissue oxygenation) with adherence to appropriate protocol might radically improve perioperative management and outcome of high-risk surgical patients $(14,15)$.

The important cofactor that may interfere with results of studies is different anaesthetic technique used in patients included in the studies (presence or absence of epidural catheter, different anaesthetics used) (16-18).

The present study tests the hypothesis that intraoperative multimodal monitoring with hemodynamic optimization and maintenance of optimal cerebral oxygen oxygenation reduces the rate of postoperative complications. Also, multimodal monitoring may reduce the duration of hospitalisation in patients undergoing major abdominal surgery.

To minimise bias all patients in both groups have received the same intraoperative anaesthetic technique with epidural postoperative analgesia and all patients underwent similar gastrointestinal surgical procedures.

\section{Methods}

Prospective, randomised trial with 2 parallel groups was conducted at the University Medical Centre (UMC)Ljubljana in years 2015 - 2018. High risk surgical patients from the Clinical department of abdominal surgery were included in the study. Adult patients that underwent one of the following major abdominal procedures were included: stomach surgery, pancreas surgery and large intestinal resections. Exclusion criteria were underage, pregnant women, laparoscopic surgery, and palliative procedures. High risk surgical patients were defined as ASA 2 or 3 with P-Possum predicted mortality $>4 \%$ (19) 
Study was approved by the National medical ethics committee of Slovenia. It was registered by ClinicalTrials.gov, Surgical Outcome and Multimodal Monitoring (SOMM) Identifier: NCT02293473. The article contains previously unpublished data from the study.

All patients scheduled for abdominal surgery were visited by a member of our team a day prior to surgery to seek an informed consent and to answer any questions. Before anaesthesia, patients were randomised into two groups using the covariate adaptive randomisation. The covariates considered were age, weight, and patients' ASA status. The groups were protocol group (PG) and control group (CG). The randomisation was carried out by member of our study team. There were 2 anaesthesiologists (who had not participated in randomisation) involved in the study. They performed intraoperative protocol determined by randomisation. Personnel conducting postoperative management and postoperative data collection were not aware of how intraoperative management was conducted or the patients' group. The gathered data and patients' group were linked after the gathering data process was finished. Brief description of perioperative management of both groups is described here. Details can be found in Appendix.

\section{Anaesthesia management}

Prior to procedure, thoracic epidural catheter (Th 7-8 or Th 9-10 for rectal surgery) insertion in left lateral position and test with $3 \mathrm{ml}$ of $2 \%$ lidocaine was performed.

After monitoring and iv-line placement, dexmedetomidine infusion was started $(0.5 \mathrm{mcg} / \mathrm{kg} / \mathrm{hour})$. Continuous infusion ended after skin suture at the end of the procedure.

Then, a standard induction to general anaesthesia (propofol, sufentanyl, rocuronium) was performed. Anaesthesia was maintained by iv infusion of propofol. Depth of anaesthesia was adjusted to maintain BIS $40-55$. Analgesia was provided by $15 \mathrm{ml} \mathrm{levobupivacaine} 0.25 \%$ epidurally, with supplementation of sufentanyl $15 \mathrm{mcg}$. 1-2 hours after epidural bolus of local anaesthetic, Patient controlled epidural analgesia was started with constant infusion rate and additional patientcontrolled boluses for postoperative analgesia (PCEA $(0.125 \%$ levobupivacaine $200 \mathrm{ml}$, morphine 4 $\mathrm{mg}$, clonidine $0.075 \mathrm{mg}$; infusion rate $5 \mathrm{ml} / \mathrm{h}$, bolus $5 \mathrm{ml}$, lock out time 30 minutes). Relaxation was provided with rocuronium and monitored with Train of four monitor. Reversal of neuromuscular block was provided with sugammadex.

Haemoglobin level was kept above $80 \mathrm{~g} / \mathrm{L}$. A fall in haemoglobin was coped with blood transfusion. Body temperature was held in the range between 36 and $37^{\circ} \mathrm{C}$.

Postoperatively, patients were transferred to postoperative recovery and thereafter to Abdominal Surgery HDUs. Postoperatively we gathered the following data: length of stay, length of stay in HDU, Re-admission to HDU or ICU, quality of wound healing, reoperations, 30-day mortality. We have observed complications (sepsis, pneumonia, acute respiratory infection, pleural effusion, myocardial infarction, pulmonary embolism, stroke, infection).

\section{Protocol group}

Monitors that calculate SV and CO from a standard radial arterial line (LiDCO Rapid, LiDCO Cardiac Sensor Systems, Cambridge, UK), unilateral cerebral oximetry NIRS monitor (INVOS, USA) monitor were applied. Baseline values of nominal stroke index (SI), cardiac index (CI), BIS, mean arterial pressure (MAP) and regional oxygen saturation ( $\mathrm{rSO} 2$ ) were recorded.

Patients have received $2 \mathrm{ml} / \mathrm{kg} / \mathrm{h}$ of balanced fluids + fluid loss replacement. The exact amount of given fluids dependent on monitored haemodynamic variables. 
$\mathrm{Cl}, \mathrm{MAP}$ and $\mathrm{SI}$ were maintained within $80 \%$ of baseline values. In case of a fall in regional cerebral oxygenation ( $\mathrm{rSO} 2$ ) in the absence of a fall in $\mathrm{Cl}$ or blood loss we adjusted ventilation so that the $\mathrm{PaCO} 2$ was kept in the high normal range $(5-5,5 \mathrm{kPa})$.

\section{Control group}

Anaesthesia in PG remained the same, there was no hemodynamic monitor. Measurement of cerebral oxygenation was also absent. Patients received $2 \mathrm{ml} / \mathrm{kg} / \mathrm{h}$ of balanced fluids and additional fluid for fluid loss replacement.

\section{Hospital discharge criteria}

Many factors influence a duration of hospital stay but is nevertheless included as one of endpoints in comparable studies (8). To reduce unintended variations, strict discharge criteria were put in place. Haemodynamically stable patient without active infection, proper wound healing and has completed first phase of rehabilitation to assisted mobility (or mobility comparable to preoperative) was discharged. If due to administrative reasons formal discharge was not possible, we considered him discharged if all the criteria were met.

\section{Statistical analysis}

Results were analysed using R: A Language and environment for statistical computing. Results of intraoperative management, postoperative creatinine results, patients' demographics and length of stay are presented as median and interquartile range. Groups were compared using Mann- Whitney $\mathrm{U}$ test, level of significance of 0.05 was considered statistically significant.

Intraoperative observations, postoperative complications and ASA classification are presented as absolute number of patients with certain intervention/observation. Groups are compared using Chisquare test or Fisher exact test where appropriate. Level of significance of 0.05 is considered statistically significant.

When comparing postoperative complications, there are several comparisons conducted on the same sample. Level of significance was adjusted accordingly to Bonferroni correction, $p$ value of 0.001 is considered statistically significant.

Power analysis was performed using simulation of results with Mann-Whitney $\mathrm{U}$ test. For a 2-day difference in length of stay, with power 0.8 and significance level $0.05,16$ patients in each group are needed. For showing 1-day difference in LOS, 40 patients in each group are needed. Calculations are based on a small pilot study with 12 patients in each group. Anticipated Cohen's - $d$ value is 0.660 for 1-day difference in length of stay. We have slightly increased the number of recruited patients due to expected loss during follow up.

Duration of hospital stay was compared as an intention to treat analysis that included patients that were otherwise excluded (Figure 1). Only 2 patients in each group were lost after randomisation due to intraoperative surgeon's decision to provide palliative treatment to those patients. $95.4 \%$ of randomised patients were followed postoperatively for complications other than hospital stay duration. 


\section{Results}

We randomised 88 patients, 44 in each group. Figure 1 shows CONSORT flow diagram of included patients. For general characteristics (age, weight, ASA status, P-possum) and duration of HDU and hospital stay 88 patients were analysed. Regarding intraoperative management and postoperative complications 84 patients were analysed, 4 were excluded after randomisation, 2 patients in PG were excluded because the intraoperative protocol was not strictly followed.

Average age of included patients was $65( \pm 12)$ years in $C G$ and $66( \pm 8)$ years in $P G(P=0.265$, MannWhitney $U$ test). Average weight was $64 \pm 10 \mathrm{~kg}$ in $C G$ and $66 \pm 12 \mathrm{~kg}$ in PG ( $p=0.177$, Mann-Whitney $U$ test).

18 patients of ASA 2 status were in CG and 16 in protocol ( $p=0,154$, Chi-square test). 24 ASA3 patients were included in the CG and 26 in $P G(p=0,117$, Chi-square test).

Median physiological P-Possum in CG was 21 (IQR7) and 20 (IQR 8) in PG ( $p=0.322$, Mann-Whitney U test). Median operative P-Possum was 13 in CG (IQR 5) and 13 (IQR 7) in PG. ( $p=0.260$, MannWhitney $U$ test).

Time of perioperative fasting was $13( \pm 2)$ hours, similar in both groups.

Median duration of the surgery (from surgical incision to the last suture) is 123 minutes in PG (interquartile range, IQR $35 \mathrm{~min}$ ), and 120 min (IQR 47min) in CG (Mann-Whitney $U$ test, $p=0,157$ )

Table 1 shows intraoperative fluid management in both groups and Table 2 intraoperative interventions regarding haemodynamic variables 
In PG, we have observed NIRS monitor results. In 7 cases (out of 42), there was a fall for more than $20 \%$ of the preoperative value during the procedure. Absolute value was never below $45 \%$.

None of the intraoperative interventions influenced hospital or high dependency unit (HDU) stay as shown in Table 3.

One person (in CG) died during hospitalisation.

Several postoperative complications were observed, distribution among groups was equal as shown in Table 4. The distribution of included patients according to risk of cardiac complications and number of observed renal and cardiac impairment is seen in Table 5.

Postoperative values of C-reactive protein (CRP) and procalcitonin (PCT) are shown in Table 6. Preoperative PCT level in all patients was within the normal laboratory reference range.

\section{Discussion}

\section{Changes in intraoperative management}

The use of extended intraoperative monitoring with assessment of fluid status and cerebral tissue oxygenation resulted in differences in intraoperative management. The amount of fluid infused was higher (median in PG was 1,7- times higher, representing high clinical significance) in PG and vasoactive drugs were used more often. That suggests trending towards more dynamic microcirculation. The most noticeable change in postoperative period (related to differences in operative management) is significant difference in procalcitonin level, perhaps due to better tissue prefusion in $\mathrm{PG}$ with patient directed fluid management. The rationale for this conclusion is further discussed below.

\section{Fluid optimisation strategy}

The results of the amount of fluids given during the surgical procedure present unexpectedly high fluid load in our PG. This group has received almost twice the amount of fluids given in the CG. Intraoperative blood loss is comparable, and PG has large positive intraoperative fluid balance. Thacker reports relation between higher fluid load and longer length of stay (20). However, length of stay was similar in both groups in our study.

Besides, questions are raised what the optimal goals of haemodynamic parameters (healthy population derived normal values, preoperative values, maximal values) should be. Studies have shown that optimizing cardiac output and oxygen delivery to higher (supra-normal) values intra- and postoperatively did not affect postoperative complications rate, intensive care unit stay or hospital length of stay (21-23). Probably the target should be maintaining patient's blood flow and oxygen delivery at preinduction levels. The question has also been raised regarding the amount of fluids. Liberal approach can lead to oedema of the intestines and other tissues which may be responsible for poor tissue healing and other complications. In abdominal surgery protocol-based fluid restriction reduced the incidence of perioperative complications such as cardiopulmonary events and disturbances of bowel motility while improving wound and anastomotic healing and reducing hospital stay in comparison to liberal fluid management $(6,7)$. One of the trials has shown $52 \%$ lower rate of major postoperative complications in restrictive group than in the conventional group (8). 
Our study presents opposite results where optimised group received larger amount of fluids. Our protocol (Appendix 1) has clearly defined steps when to add inotropes or fluid. One reason for fluid load would be the vasodilatation due to epidural analgesia (all patients in our study have epidural analgesia), although vasoconstrictor (phenylephrine) in boluses was predicted for counter the effect.(24) In comparing studies $60-80 \%$ of patients included have epidural analgesia $(18,25)$. Despite large difference in volume of infused fluids, there is no difference in length of stay. Lopes reports significant decrease in ICU and hospital stay in intervention group with an even larger difference in the number of infused crystalloids and colloids. He reports a total volume of infused fluids $7 \mathrm{ml} / \mathrm{kg} / \mathrm{h}$ in CG (roughly the same as in our study) and $21 \mathrm{ml} / \mathrm{kg} / \mathrm{h}$ in intervention group $(12,5$ in our study). But still are the results of complications and length of stay different to the conclusions of the above mentioned studies or than in our study (26). The choice of fluid also differs greatly. Harten et all reports no difference in renal function between control and optimised groups (17). Optimised group has received larger volume of fluids, especially, although not exclusively colloids (27). Other studies of abdominal patients can offer opposite conclusions, with lower volume of fluid infused in optimised group (28). In this study, the difference in hospital stay is not significant. Some studies do not report difference in total volume of infused fluids, but there is still difference in outcome (29). That can serve us as a reminder, that we should compare not only amount of fluids infused, but also the timing of infusions. Rare studies report other factors that greatly affect patient's fluid status at the beginning, for example how long prior to procedure are fasted, are there fast track protocols implemented and so on. When trying to explain why sometimes one fluid regime (for example restrictive) improves the outcome for the most, but not for all, we must realise that instead of restrictive or liberal there is only patient directed fluid regime. Every patient should receive as much fluids as needed and at an appropriate timing (30). All the rest seems to be just generalisations that work for certain (sometimes large) subpopulations.

\section{Differences in the use of vasopressors}

Significantly more patients in PG require vasopressor support with phenylephrine. Some papers suggest that anaesthetic after induction also causes venodilatation and not only arteriolar vasodilation (and consequently the fall in MAP due to a shift of volume out of the arterial tree into the dilated venous compartment) (24,31-33). Phenylephrine infusion before induction minimizes this effect, but this is hardly the comprehensive explanation of the difference. To keep hemodynamic parameters as close to starting values as possible, the anaesthetist in PG has probably reacted sooner than in CG. Nonetheless, phenylephrine intervention is predicted in the protocol of both groups (Appendix 1) due to vasodilation after epidural bolus. In CG, if MAP were maintained to some extent (due to reflex mechanisms) there was no information about hemodynamic changes that would require intervention (fall in cardiac output and stroke index). Number of falls of MAP below $70 \mathrm{mmHg}$ and $50 \mathrm{mmHg}$ is similar in both groups, but that does not mean that duration of hypotension is the same. Together with higher volume of infused fluids this might suggest that in PG higher $\mathrm{Cl}$ or more dynamic circulation was targeted.

\section{Monitoring depth of anaesthesia}

BIS was used in both groups. This is according to hospital policy, since total intravenous infusion was used in order to prevent intraoperative awareness (34). In the context of multimodal monitoring, we omit an important variable that without doubt influences the outcome. Probably not only cognitive decline, but mortality and morbidity in general are related to too deep anaesthesia, common occurrence without monitoring, especially in elderly (35). There was a statistically significant difference among groups but considering target values $40-55$ it is hardy of clinical importance. 


\section{The role of cerebral oximetry}

Our study does not confirm the benefit of using cerebral oximetry monitor during major abdominal surgery, at least does not influences outcomes as are presented in this study. Can monitoring oxygenation of the brain really be considered as a monitor of overall tissue oxygenation? In our opinion, due to autoregulation of the brain blood flow, this assumption is wrong, until it is compared to other monitors of tissue oxygenation (36). Incidence of renal impairment can be considered one of the measures of adequate oxygenation. There is no difference in postoperative renal impairment in our study. Another question is what are the possible actions in case of fall for more than $10 \%$ ? Apart from blood transfusion (if justified by laboratory values) the only answer would be to increase hemodynamic parameters to supranormal values, that was already showed to be without benefit (22). Only 3 occurrences of RBC transfusion are recorded in our study but decrease for more than $20 \%$ in NIRS value from starting point was recorded in 7 out of 42 patients, despite hemodynamic values were optimised. However, the absolute value was never below $45 \%$, that is considered critical value (37).

\section{Postoperative complications and length of stay}

At first glance, we can conclude that combination of hemodynamic monitor and measurement of cerebral oxygenation do not provide any benefit to patients in our study. Neither length of stay in HDU, nor the hospital stay do not decrease in PG. There are some postoperative complications such as the need for revision surgery, indication for antibiotic treatment third day after procedure or readmission to HDU that largely occur only in the CG. Only comparison of individual complication does not show a statistically significant difference, but if we sum up all three, there is obvious and statistically significant difference. Some other studies report more convincing, but similar results (29).

There is a significant difference in highest postoperative levels (in first 3 days) of procalcitonin. The level of procalcitonin rises in a response to a pro-inflammatory stimulus, especially of bacterial origin. Median value in CG is above the reference range. At the same time, levels of $C$ reactive protein do not differ among groups. Patients in the CG may be more prone to bacterial infections. Higher level of infections in non-optimised group is also reported in literature (8).

Troponin leak was observed in 3 patients in PG. The raise is only marginally above the laboratory threshold value for positive. Acute myocardial infarction was ruled out in those patients with a high degree of confidence. Anyway, this can be related to higher fluid load in PG.

\section{Strengths and limitations of the study}

Patients involved in the study are very homogenous in terms of surgical procedures, perioperative surgical management, and comorbidities. Type of anaesthesia was the same (TIVA with propofol and epidural analgesia) in all observed patients. Comparing to other prospective studies, the number of included patients is comparable (38).

Probably, multimodal monitoring would provide more benefit, if used throughout entire HDU stay not only during surgical procedure.

\section{Conclusions}

In our study, combined use of hemodynamic and cerebral oxygenation monitoring does not significantly decrease postoperative morbidity, length of stay in HDU or hospital stay. Median postoperative value of procalcitonin was significantly higher in CG and was above laboratory reference range. There is a difference in intraoperative amount of infused fluids, larger volume in PG. 


\section{References}

1. Sandham JD, Hull RD, Brant RF, Knox L, Pineo GF, Doig CJ, et al. A Randomized, Controlled Trial of the Use of Pulmonary-Artery Catheters in High-Risk Surgical Patients. N Engl J Med. 2003 Jan 2;348(1):5-14.

2. Walsh SR, Tang T, Bass S, Gaunt ME. Doppler-guided intra-operative fluid management during major abdominal surgery: Systematic review and meta-analysis. Int J Clin Pract. 2008;62(3):466-70.

3. Gurgel ST, Do Nascimento P. Maintaining tissue perfusion in high-risk surgical patients: A systematic review of randomized clinical trials. Anesth Analg. 2011;112(6):1384-91.

4. Navarro LHC, Bloomstone JA, Auler JOC, Cannesson M, Rocca G Della, Gan TJ, et al. Perioperative fluid therapy: a statement from the international Fluid Optimization Group. Perioper Med. 2015;4(1).

5. Saugel B, Flick M, Bendjelid K, Critchley LAH, Vistisen ST, Scheeren TWL. Journal of clinical monitoring and computing end of year summary 2018: hemodynamic monitoring and management. J Clin Monit Comput. 2019;33(2):211-22.

6. Giglio MT, Marucci M, Testini M, Brienza N. Goal-directed haemodynamic therapy and gastrointestinal complications in major surgery: A meta-analysis of randomized controlled trials. Br J Anaesth. 2009;103(5):637-46.

7. Grocott MPW, Dushianthan A, Hamilton MA, Mythen MG, Harrison D, Rowan K. Perioperative increase in global blood flow to explicit defined goals and outcomes after surgery: A cochrane systematic review. Br J Anaesth. 2013;111(4):535-48.

8. Pearse RM, Harrison DA, MacDonald N, Gillies MA, Blunt M, Ackland G, et al. Effect of a Perioperative, Cardiac Output-Guided Hemodynamic Therapy Algorithm on Outcomes Following Major Gastrointestinal Surgery. Jama. 2014;311(21):2181.

9. Murkin JM, Arango M. Near-infrared spectroscopy as an index of brain and tissue oxygenation. Br J Anaesth. 2009;103(SUPPL.1):3-13.

10. Slater JP, Guarino T, Stack J, Vinod K, Bustami RT, Brown JM, et al. Cerebral Oxygen Desaturation Predicts Cognitive Decline and Longer Hospital Stay After Cardiac Surgery. Ann Thorac Surg. 2009;87(1):36-45.

11. Bisgaard J, Gilssa T, Ronholm E, Toft P. Optimising stroke volume and oxygen delivery in abdominal aortic surgery: a randomised controlled trial. Acta Anaesthesiol Scand. 2013 Feb;57(2):178-88.

12. Chan MTV, Cheng BCP, Lee TMC, Gin T. BIS-guided Anesthesia Decreases Postoperative Delirium and Cognitive Decline. J Neurosurg Anesthesiol. 2013;25(1):33-42.

13. Ballard C, Jones E, Gauge N, Aarsland D, Nilsen OB, Saxby BK, et al. Optimised anaesthesia to reduce post operative cognitive decline (POCD) in older patients undergoing elective surgery, a randomised controlled trial. PLoS One. 2012;7(6):1-9.

14. Green D, Paklet L. Latest developments in peri-operative monitoring of the high-risk major surgery patient. Int J Surg. 2010;8(2):90-9.

15. Fernandes A, Rodrigues J, Antunes L, Lages P, Santos CS, Moreira-Gonçalves D, et al. Development of a preoperative risk score on admission in surgical intermediate care unit in 
gastrointestinal cancer surgery. Perioper Med. 2020;9(1):1-9.

16. Kaufmann T, Clement RP, Scheeren TWL, Saugel B, Keus F, van der Horst ICC. Perioperative goal-directed therapy: A systematic review without meta-analysis. Acta Anaesthesiol Scand. 2018;62(10):1340-55.

17. Harten J, Crozier JEM, McCreath B, Hay A, McMillan DC, McArdle CS, et al. Effect of intraoperative fluid optimisation on renal function in patients undergoing emergency abdominal surgery: A randomised controlled pilot study (ISRCTN 11799696). Int J Surg. 2008;6(3):197-204.

18. Benes J, Chytra I, Altmann P, Hluchy M, Kasal E, Svitak R, et al. Intraoperative fluid optimization using stroke volume variation in high risk surgical patients: results of prospective randomized study. Crit Care. 2010;14(3):R118.

19. Prytherch DR, Whiteley MS, Higgins B, Weaver PC, Prout WG, Powell SJ. POSSUM and Portsmouth POSSUM for predicting mortality. Br J Surg. 1998;85(9):1217-20.

20. Thacker JKM, Mountford WK, Ernst FR, Krukas MR, Mythen M (Monty) G. Perioperative Fluid Utilization Variability and Association With Outcomes. Ann Surg. 2016;263(3):502-10.

21. Shoemaker WC, Appel PL, Kram HB, Waxman K, Lee TS. Prospective trial of supranormal values of survivors as therapeutic goals in high-risk surgical patients. Chest. 1988;94(6):117686.

22. Velmahos GC, Demetriades D, Shoemaker WC, Chan LS, Tatevossian R, Wo CC, et al. Endpoints of resuscitation of critically injured patients: normal or supranormal? A prospective randomized trial. Ann Surg. 2000;232(3):409-18.

23. Kim HJ, Kim EJ, Lee HJ, Min JY, Kim TW, Choi EC, et al. Effect of goal-directed haemodynamic therapy in free flap reconstruction for head and neck cancer. Acta Anaesthesiol Scand. 2018;62(7):903-14.

24. Jozwiak M, Rex S, Bendjelid K. Boosting systemic pressure with phenylephrine: arterial or venous modulation? J Clin Monit Comput. 2018;32(6):967-8.

25. Zheng H, Guo H, Ye J, Chen L, Ma H. Goal-Directed Fluid Therapy in Gastrointestinal Surgery in Older Coronary Heart Disease Patients: Randomized Trial. World J Surg. 2013;37(12):2820-9.

26. Lopes MR, Oliveira MA, Pereira V, Lemos I, Auler J, Michard F. Goal-directed fluid management based on pulse pressure variation monitoring during high-risk surgery: a pilot randomized controlled trial. Crit Care. 2007;11(5):R100.

27. Benes J, Giglio M, Brienza N, Michard F. The effects of goal-directed fluid therapy based on dynamic parameters on post-surgical outcome: a meta-analysis of randomized controlled trials. Crit Care. 2014;18(5):584.

28. Forget $\mathrm{P}$, Lois F, De Kock M. Goal-directed fluid management based on the pulse oximeterderived pleth variability index reduces lactate levels and improves fluid management. Anesth Analg. 2010;111(4):910-4.

29. Salzwedel C, Puig J, Carstens A, Bein B, Molnar Z, Kiss K, et al. Perioperative goal-directed hemodynamic therapy based on radial arterial pulse pressure variation and continuous cardiac index trending reduces postoperative complications after major abdominal surgery: a multi-center, prospective, randomized study. Crit Care. 2013;17(5):R191.

30. Kirov MY, Kuzkov V V, Molnar Z. Perioperative haemodynamic therapy. Curr Opin Crit Care. 2010;16(4):384-92. 
31. Green DW. Cardiac output decrease and propofol: What is the mechanism? Vol. 114, British Journal of Anaesthesia. 2015. p. 163-4.

32. Wolff CB, Green DW. Clarification of the circulatory patho-physiology of anaesthesia Implications for high-risk surgical patients. Int J Surg. 2014;12(12):1348-56.

33. Moller Petrun A, Kamenik M. Bispectral index-guided induction of general anaesthesia in patients undergoing major abdominal surgery using propofol or etomidate: a double-blind, randomized, clinical trial. Br J Anaesth. 2013;110(3):388-96.

34. Avidan MS, Zhang L, Burnside BA, Finkel KJ, Searleman AC, Selvidge JA, et al. Anesthesia Awareness and the Bispectral Index. N Engl J Med. 2008 Mar 13;358(11):1097-108.

35. Bidd H, Tan A, Green D. Using bispectral index and cerebral oximetry to guide hemodynamic therapy in high-risk surgical patients. Perioper Med. 2013;2(1):11.

36. Klijn E, van Velzen MHN, Lima AP, Bakker J, van Bommel J, Groeneveld ABJ. Tissue perfusion and oxygenation to monitor fluid responsiveness in critically ill, septic patients after initial resuscitation: a prospective observational study. J Clin Monit Comput. 2015;29(6):707-12.

37. Scheeren TWL, Schober P, Schwarte LA. Monitoring tissue oxygenation by near infrared spectroscopy (NIRS): background and current applications. J Clin Monit Comput. 2012;26(4):279-87.

38. Challand C, Struthers R, Sneyd JR, Erasmus PD, Mellor N, Hosie KB, et al. Randomized controlled trial of intraoperative goal-directed fluid therapy in aerobically fit and unfit patients having major colorectal surgery. Br J Anaesth. 2012;108(1):53-62.

Table 1: Intraoperative fluid management

\begin{tabular}{|l|l|l|l|}
\hline & $\begin{array}{l}\text { Control group } \\
\text { Median (interquartile } \\
\text { range) } \mathrm{ml}\end{array}$ & $\begin{array}{l}\text { Protocol group } \\
\text { Median (interquartile } \\
\text { range) } \mathrm{ml}\end{array}$ & $\begin{array}{l}\text { P value } \\
\text { (Mann -Whitney U } \\
\text { test) }\end{array}$ \\
\hline $\begin{array}{l}\text { Intraoperative blood } \\
\text { loss }\end{array}$ & $300(425)$ & $500(500)$ & 0.182 \\
\hline RBC transfusion & $0(0)$ & $0(0)$ & 0.185 \\
\hline FFP transfusion & $0(0)$ & $0(0)$ & 1 \\
\hline Platelet transfusion & $0(0)$ & $0(0)$ & 0.317 \\
\hline $\begin{array}{l}\text { Intraoperative fluid } \\
\text { balance }\end{array}$ & $+375(438)$ & $+1300(1063)$ & $0.000^{1}$ \\
\hline $\begin{array}{l}\text { Intraoperative urinary } \\
\text { output }\end{array}$ & $205(100)$ & $300(200)$ & 0.078 \\
\hline
\end{tabular}

1 - indicates statistically significant difference 


\begin{tabular}{|c|c|c|c|}
\hline & $\begin{array}{l}\text { Control group } \\
\text { (Number of patients out } \\
\text { of } 42 \text { with certain } \\
\text { observation/intervention) }\end{array}$ & $\begin{array}{l}\text { Protocol group } \\
\text { (Number of patients out } \\
\text { of } 42 \text { with certain } \\
\text { observation/intervention) }\end{array}$ & $\begin{array}{l}P \\
\text { value }\end{array}$ \\
\hline $\begin{array}{l}\text { Bolus of phenylephrine during } \\
\text { procedure }\end{array}$ & 31 & 38 & $\begin{array}{l}0.043^{1,} \\
2\end{array}$ \\
\hline $\begin{array}{l}\text { Vasoactive support with } \\
\text { norepinephrine }\end{array}$ & 1 & 2 & $0.500^{3}$ \\
\hline $\begin{array}{l}\text { Mean arterial pressure less than } \\
70 \mathrm{mmHg} \text { anytime during } \\
\text { procedure }\end{array}$ & 31 & 36 & $0.226^{2}$ \\
\hline $\begin{array}{l}\text { Mean arterial pressure less than } \\
50 \mathrm{mmHg} \text { anytime during } \\
\text { procedure }\end{array}$ & 7 & 8 & $0.353^{2}$ \\
\hline
\end{tabular}

1 - statistically significant difference

2-Pearson Chi-square

3 - Fisher's Exact Test

Table 3: Length of stay comparison

\begin{tabular}{|l|l|l|l|}
\hline & $\begin{array}{l}\text { Control group Median } \\
\text { (Interquartile range) } \\
\text { days }\end{array}$ & $\begin{array}{l}\text { Protocol group } \\
\text { Median (Interquartile } \\
\text { range) days }\end{array}$ & $\begin{array}{l}\text { P value } \\
\text { (Mann - Whitney U } \\
\text { test) }\end{array}$ \\
\hline $\begin{array}{l}\text { Length of stay in } \\
\text { hospital }\end{array}$ & $9(8)$ & $9(5.5)$ & 0.851 \\
\hline Length of stay in HDU & $4(3)$ & $3(1.3)$ & 0.122 \\
\hline
\end{tabular}

Table 4: List of postoperative complications in first three days after the procedure in both groups

\begin{tabular}{|l|l|l|l|}
\hline $\begin{array}{l}\text { Postoperative } \\
\text { complication/intervention }\end{array}$ & $\begin{array}{l}\text { Control group } \\
\text { (Number of patients out } \\
\text { of 42 with certain } \\
\text { observation/intervention) }\end{array}$ & $\begin{array}{l}\text { Protocol group } \\
\text { (Number of patients out } \\
\text { of 42 with certain } \\
\text { observation/intervention) }\end{array}$ & Palue $^{*}$ \\
\hline Re-admission to the HDU & 5 & 1 & $0.136^{1}$ \\
\hline Admission to ICU & 2 & 0 & $0.247^{2}$ \\
\hline Revision surgery & 6 & 0 & $0.026^{1}$ \\
\hline $\begin{array}{l}\text { Patient has died before } \\
\text { discharge }\end{array}$ & 1 & 0 & $0.500^{2}$ \\
\hline $\begin{array}{l}\text { Complications related to } \\
\text { operative procedure } \\
\text { (dehiscence, } \\
\text { inflammation) first day } \\
\text { after procedure }\end{array}$ & 0 & 2 & $0.494^{2}$ \\
\hline
\end{tabular}




\begin{tabular}{|l|l|l|l|}
\hline $\begin{array}{l}\text { Complications related to } \\
\text { operative procedure } \\
\text { (dehiscence, } \\
\text { inflammation) third day } \\
\text { after procedure }\end{array}$ & 3 & 2 & $1^{2}$ \\
\hline $\begin{array}{l}\text { Transfusion of RBC } \\
\text { required in first day after } \\
\text { procedure }\end{array}$ & 2 & 0 & $0.513^{2}$ \\
\hline $\begin{array}{l}\text { Transfusion of RBC } \\
\text { required second or third } \\
\text { day after procedure }\end{array}$ & 1 & 2 & $0.500^{2}$ \\
\hline
\end{tabular}

${ }^{*}$ due to multiple comparisons $\mathrm{p}$ value significance was adjusted accordingly to Bonferroni correction (significant $p$ value for variables in the table was $<0.001$ )

1 - Pearson Chi-square

2 - Fisher's Exact Test

Table 5: Number of patients according to Lee's Revised Cardiac Risk Index in both groups. Comparison of postoperative rise of troponin I above the laboratory reference range and rise in creatinine ( $\geq 0.3 \mathrm{mg} / \mathrm{dL}$ increase in creatinine level or 1.5 times baseline (KIDGO stage 1) is added.

\begin{tabular}{|l|c|c|c|}
\hline $\begin{array}{l}\text { Lee's Revised Cardiac } \\
\text { Risk Index }\end{array}$ & $\begin{array}{l}\text { Control group } \\
\text { (number of patients) }\end{array}$ & $\begin{array}{l}\text { Protocol group } \\
\text { (number of patients) }\end{array}$ & P value \\
\hline II & 26 & 27 & $0.855^{1}$ \\
\hline III & 12 & 10 & $0,500^{2}$ \\
\hline IV & 4 & 5 & $0,241^{2}$ \\
\hline $\begin{array}{l}\text { Acute kidney } \\
\text { impariment }\end{array}$ & 3 & 4 & 3 \\
\hline Troponin leak & 0 & 3 &
\end{tabular}

1 - Chi - square test

2 - Fisher exact test

Table 6: Comparison of postoperative (3 days after surgery) levels of CRP and PCT

\begin{tabular}{|l|l|l|l|}
\hline & $\begin{array}{l}\text { Control group } \\
\text { (Interquartile } \\
\text { range) }\end{array}$ & $\begin{array}{l}\text { Protocol } \\
\text { group } \\
\text { (Interquartile } \\
\text { range) }\end{array}$ & P value \\
\hline $\begin{array}{l}\text { Median C-reactive protein level (difference } \\
\text { between highest postoperative level in 3 days and } \\
\text { preoperative level) } \\
\text { Laboratory reference range (0-5 mcg/L) }\end{array}$ & $125(118)$ & $115(122)$ & $0.106^{1}$ \\
\hline $\begin{array}{l}\text { Median procalcitonin level (highest postoperative } \\
\text { value in first 3 days) } \\
\text { Laboratory reference range (0-0.50 mcg/L) }\end{array}$ & $0.75(3.19)$ & $0.3(0.88)$ & $0.001^{1,2}$ \\
\hline
\end{tabular}

1 - independent samples Mann-Whitney $\mathrm{U}$ test

2 - statistically significant difference 
Figures

\section{Image not available with this version}

Figure 1

This image was omitted by the authors in this version of the paper 